\title{
Increasing Household Consumption of Iodised Salt: a Community Engagement Project in Khyber Pakhtunkhwa, North West Pakistan
}

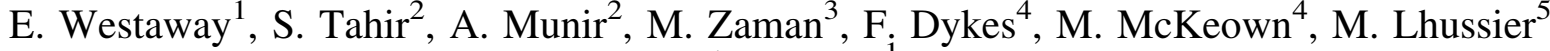 \\ and N. Lowe ${ }^{1}$ \\ ${ }^{1}$ International Institute of Nutritional Sciences and Food Safety Studies, University of Central Lancashire, Preston, PRI \\ 2HE, UK, ${ }^{2}$ Abaseen Foundation, Peshawar, Pakistan, ${ }^{3}$ Khyber Medical University, Peshawar, Pakistan, ${ }^{4}$ Maternal and \\ Infant Nutrition and Nurture Unit, University of Central Lancashire, Preston, PR1 2HE, UK and ${ }^{5}$ Faculty of Health, \\ Community and Education Studies, Northumbria University, Newcastle upon Tyne, NE1 8ST, UK
}

Pakistan's Iodine Deficiency Disorders Control Programme (IDDCP) was launched in 1994 and has reduced the IDD prevalence, with the country being considered to have optimal iodine nutrition; ${ }^{(1)}$ however, approximately half of Pakistan's population of 200 million are affected with IDD to some degree ${ }^{(2)}$. Data from the recent National Nutrition Survey in Pakistan revealed that among children 6-12 years of age, $63.3 \%$ have adequate iodine status, $24.4 \%$ are mildly deficient, $10.1 \%$ moderately deficient and $2.2 \%$ severely iodine deficient at the national level. There is a marked provincial variation and within Khyber Pakhtunkhwa (KP), 25.7\% of children 6-12 years of age have some form of $\operatorname{IDD}^{(2)}$.

The purpose of this research was to undertake an investigation into the knowledge of the benefits of iodised salt, and its use in a rural brick kiln community located in Peshawar District, KP. This community of 5,000 households is composed of Afghan refugees, internally displaced people and the host population, living in a context of chronic rural poverty where children are born into bonded labour. A survey of 1,043 households was conducted in July 2012, which included questions on household demographics, uptake of primary health care services, and use and knowledge of iodised salt. In January 2013, a survey of 28 shopkeepers in the local bazaar was conducted about the types of salt stocked, purchasing patterns of community members, knowledge of iodised salt and ways of increasing household uptake of iodised salt.

Findings showed that only $2.6 \%$ of households reported use of iodised salt and $3.5 \%$ knew of the benefits of iodised salt, which included goitre prevention $(2.6 \%)$, and improved mental capacity $(0.3 \%)$ and physical activity $(0.6 \%)$. $67.9 \%$ of shopkeepers stocked iodised salt, which cost Rs. 5-7 more than simple salt, and reasons why people did not buy it included expense (35.7\%), believed negative impact on reproduction $(42.9 \%)$ and lack of awareness $(7.1 \%)$.

In terms of public health implications, this study shows that members of the brick kiln community in KP have an elevated risk of IDDs due to low household consumption and knowledge about iodised salt, coupled with other factors, such as lack of dietary sources, iodine depleted soils, goitrogenic effects of foods, industrial pollutants from the brick kilns, smoking and micronutrient/mineral deficiencies, and chronic poverty. An intervention to raise awareness of the importance of iodised salt, and designed by members of the community, is currently being implemented in response to these findings.

This work was supported by an International Engagement Grant from the Wellcome Trust.

1. Andersson M, Karumbunathan V \& Zimmermann MB (2012) Global iodine status in 2011 and trends over the past decade. J Nutr 142, 744-750.

2. Agha Khan University, Pakistan Medical Research Council \& Government of Pakistan (2011) National Nutrition Survey Pakistan 2011. http:// pakresponse.info/LinkClick.aspx?fileticket=BY8AFPcHZQo\%3D\&tabid accessed 2 April 2013). 